\title{
The Role of Ki67 and p16INK4a Biomarkers on Conventional Cell Blocks to Differentiate Post Radiation Dysplasia from Cervical Cancer in Post Therapeutic Surveillance Cytology
}

\author{
Fanny. S. Desai ${ }^{1}$, Rajesh Korant ${ }^{2}$, Mehul Gohil ${ }^{2}$, Lisam Shanjukumar Singh ${ }^{3}$ \\ ${ }^{1}$ Department of Surgical Pathology, Himalaya Cancer Hospital and Research Center, Vadodara, Gujarat, India. ${ }^{2}$ Department of \\ Radiation Oncology, Himalaya Cancer Hospital and Research Center, Vadodara, Gujarat, India. ${ }^{3}$ Department of Biotechnology, \\ Cancer Biology Division, Manipur University, Imphal, Manipur, India.
}

\begin{abstract}
Aim and objectives: Diagnostic accuracy of post therapy Papanicolaou (pap) tests is low, as it is difficult to differentiate benign from malignant lesions due to post radiation cellular changes. Here we have evaluated the role of biomarker p16INK4a and Ki67on conventional cell blocks (CCBs) in post therapeutic surveillance of cervical cancer to detect residual disease and site recurrence. We have also evaluated CCBs as a primary screening test. Material and Methods: In this cross-sectional study, patients who were diagnosed as cervical cancer before one year were followed between periods of April 2018-April 2019. We collected conventional pap smears and samples in $10 \%$ neutral buffered formalin for CCBs. The immunohistochemistry was performed on all cell blocks using Ki67 and p16INK4a as primary antibodies. Results: Out of total 35 cases, recurrences and residual disease were diagnosed in 8 cases. Sensitivity, specificity, diagnostic accuracy for pap, cell blocks and p16INK4a for detecting cervical cancer were $75 \%, 74.07 \%, 88.57 \% ; 100 \%, 88.89 \%, 91.43 \%$ and $37.50 \%, 96.30 \%$ and $82.86 \%$ respectively. We observed that Ki67 labeling index $\geq 20 \%$ had a diagnostic accuracy of $100 \%$. Conclusion: Our findings suggest that Ki67 labeling index $\geq 20 \%$ on CCBs can differentiate residual and recurrent cancer from post radiation dysplasia in post therapy surveillance cytology ( $p$ value $<0.001$ ). We also observed that $C C B s$ has better diagnostic accuracy than pap test (Mac Nemar $p$ value, 0.027). We did not found p16INK4A much useful as a biomarker in evaluation recurrence/residual disease.
\end{abstract}

Keywords: Post therapeutic surveillance- cell blocks- Ki 67 labelling index- diagnostic accuracy

Asian Pac J Cancer Biol, 6 (2), 111-116

\section{Introduction}

Although the proportion of cervical cancer deaths among all cancer deaths decreased from $8 \cdot 2 \%$ in 2008 , to $7 \cdot 5 \%$ in 2018 , it is still the fourth most common cancer in women worldwide and leading cause of cancer deaths in women particularly in low resourced countries [1]. A treatment of cervical cancer varies according to the stage. The main treatment of early stage cancer is either surgery or radiotherapy (RT). For stages IB2 to IVA and those patients who are not candidates for surgery, concurrent chemo radiation $(\mathrm{CT}+\mathrm{RT})$ is the treatment of choice [2-3] The main purpose of follow up programmes is to detect recurrent disease early [4]. According to Society of Gynaecologic oncology's new
Submission Date: 02/18/2021 Acceptance Date: 04/18/2021

\footnotetext{
Corresponding Author:

Dr. Fanny Desai

Department of Surgical Pathology, Himalaya Cancer Hospital and Research Center, Vadodara, Gujarat, India.

Email: fannydesai@gmail.com
} 
occur after radiation therapy known as post radiation dysplasia (PRD) and reported to occur in $18.7-26 \%$ in treated patients with RT [11]. They occur at a varying period of time following irradiation and do not necessarily represent invasive cancer. A post radiation changes usually subside 3-6 months following treatment, however in some patients they may persist for 30 years or more [12-13]. Recently, a Positron Emission Tomography - Computed Tomography (PET/CT) scan is considered as a sensitive test (90\%-97\%) in detecting cervical cancer recurrences, but its specificity is low (71\%-76\%) and still need to be confirmed by histopathology [14-15]. The main pitfall is that the inflammatory response at primary site caused by radiation therapy can be hyper metabolic and follow up PET-CT need to be performed after the inflammatory response abate, i.e. 8-12 weeks after radiation therapy. The PET/CT scan still cannot detect residual cancer during therapy or immediately after completion of treatment [15-16].

Although pap test is effective to screen abnormal cervical cytology before therapy, it is not very useful after therapy because of radiation-induced changes. The Dual biomarkers on pap smears and cell blocks have improved the sensitivity and sensitivity of cervical cancer detection before therapy; however, their role in post therapy surveillance is not known. In the present study, we evaluated biomarkers Ki67 and p16INK4a on conventional cell blocks (CCBs) preparations in detecting site recurrence and residual disease. We also evaluated accuracy of cell blocks as the primary screening technique in this scenario and compared it with conventional pap test.

\section{Materials and Methods}

After Institutional Ethical Committee approval, patients diagnosed and treated as cervical cancer before one year were identified from our institute data base and were followed between periods of April 2018-April 2019. The cross sectional efficacy was evaluated for pap test, CCB test, Ki67 and p16INK4a biomarkers.

\section{Sample collection and cell block preparation}

Three Conventional Pap smears were made using sterile wooden spatulas and endocervical brushes. The ends of both sample collectors were then cut and placed in 10\% neutral buffered formalin. Another sample was taken with a wooden spatula and was placed into the same fixative vial without dispersion. The pap smears were stained with Papanicolau stain. The CCBs were prepared from the formalin-fixed specimens using a method described by Desai and Lisam et al [17]. Biomarker analysis on CCBs was carried out using immunohistochemical technique. We used p16INK4a (Biogenix, Fremont, USA, clone G175-405) and Ki67 (Dako, Denmark, clone MIB 1) as primary antibodies and Dako envision system (Dako, Denmark) as detection kit. Histological sections from cervical cancer were used as the positive control, and we omitted the primary antibody as the negative control.

\section{Examination and reporting of samples}

We used the Bethesda 2014 system for classification on both pap smears and cell blocks [18]. To simplify lesions on pap smears and cell blocks, we reclassified them as atrophy or NILM (negative for intraepithelial lesion or malignancy) (Figure $1 \mathrm{~A}$ and $\mathrm{D}$ ), post radiation dysplasia (PRD) (Figure 2B), suspicious for malignancy (Figure 2C) and malignant (Figure 3A, D). All ASCUS (atypical squamous cell of undetermined significance), LSIL (Low grade squamous intraepithelial lesion), AGUS (Atypical glandular cells of undetermined significance) and radiation-induced changes were put in PRD category. All the lesions showing ASC-H and HSIL (High grade squamous intraepithelial lesion) were reclassified as suspicious for malignancy. A cellularity was considered adequate when $>2000$ cells/slide present. The $\mathrm{p} 16 \mathrm{INK} 4 \mathrm{a}$ expressions were reported as negative (Figure 1E), weak positive (Figure 1B and Figure $3 \mathrm{~B}$ ) and strong positive (Figure 3D). Weak positive and negative expressions were considered as 'disease absent' and strong expression was considered as 'disease present'. The Ki67 labeling index was calculated as a hot spot count by 'Image J software'. Inflammatory cells (Figure 1A, D) were identified on morphology examination and omitted for calculation of Ki 67 index. Only epithelial cells of interest in fragments or sheets displaying strong dot nuclear expression were considered for Ki 67 hot spot count (Figure 3C, F).

\section{Reference standard and treatment referral}

All participants were advised complete physical examination and CT scan, and biopsy in indicated cases, and diagnosis of recurrent/residual disease were made after combinations of all the modalities according to Society of Gynaecologic oncology's new recommendations for post treatment surveillance. The patients with disease were classified according to $8^{\text {th }}$ AJCC classification $[4,3,19]$ and referred for the treatment. The patients without disease were put under follow up programme.

\section{Statistical analysis}

The statistical analysis was performed using IBM SPSS Statistics 21. In our study, Pearson's chi-square test was used to compare the variables. We used Cohen's kappa agreement to identify the similarity between diagnostic tests and reference standard, and MacNemar test to compare Pap test and CCB test. ROC curves were plotted for all the tests (Figure 4) and alpha value $<0.05$ was considered as statistically significant. We did not do any analysis for verification bias as it would be impractical to do biopsies in un-indicated cases.

\section{Results}

We collected samples from 35 patients who have undergone treatment for cervical cancer before one year and found that mean age of the patients was 52.42 years (minimum 35 years and maximum 72 years). Cervical cancer stages at presentation were: stage IA 8 (22.9\%), IB 1 (2.9\%), IIA 2 (5.7\%), IIB 10 (28.6\%), IIIA 1 (2.9\%), IIIB $10(28.6 \%)$ and IVA $3(8.6 \%)$. Hysterectomy was done in 


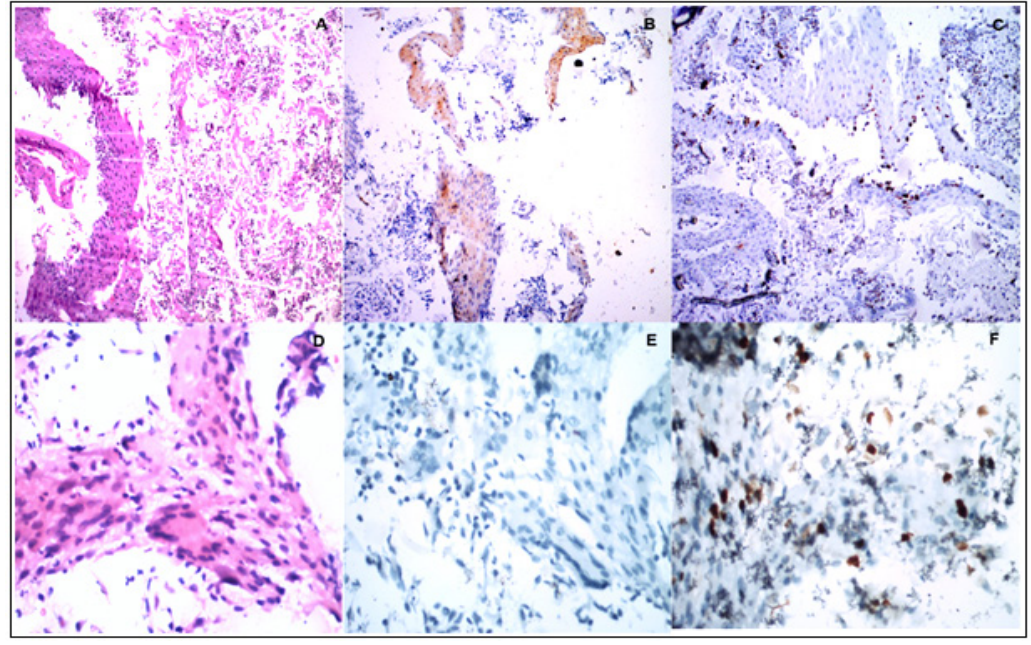

Figure 1. (A) Atrophic Squamous Epithelium with Inflammation H\&E, 4x B) p16INK4a Weak Expression 4x C) Ki 67 10x (D) Atrophic Inflammatory Smear with some Atypia H\&E 40x (E) p16 INK4a Negative Expression 40x (F) Ki 67, Inflammatory Cells 40x

$10(28.6 \%)$ cases, CT+RT was given in $23(65.7 \%)$ cases and hysterectomy \& $\mathrm{CT}+\mathrm{RT}$ in $2(5.7 \%)$ cases.

All the pap smears showed adequate cellularity for the diagnosis. On CCBs, we found adequate cellularity in 33 (94\%) cases. Two cases were partially inadequate; however, we could carry out immunohistochemistry (IHC) on it. The cell blocks lesions with their respective p16INK4a and Ki67 expressions were presented in Figure 1, 2, 3. On conventional pap smears examination, we found atrophy in $15(42.9 \%)$, radiation atypia in 07 $(20.6 \%)$, suspicious of malignancy in $5(14.3 \%)$ and cancer in 8 (22.9) cases. While cell blocks examination showed atrophy in $21(60 \%)$, radiation atypia in $3(8.6 \%)$, suspicion of cancer in $6(17.1 \%)$ and cancer in 5 cases $(14.3 \%)$. The p16INK4a expression was negative in 19 $(54.3 \%)$ cases, weak in $12(34.3 \%)$ cases and strong in $4(11.4 \%)$ cases. We observed $\mathrm{Ki} 67$ index $<5 \%$ in 22 $(62.8 \%)$ of the cases, $5-15 \%$ in $05(14.3 \%), 16-19 \%$ in 1 $(2.86 \%)$ and $\geq 20 \%$ in $7(20 \%)$ of the cases. On cell blocks, mean Ki67 labeling indices for NILM/atrophy, radiation dysplasia and malignancy cases were $2.5 \%$ (min $0 \%$ to $\max 10 \%), 3.7 \%(\min 3 \%$ to $\max 40 \%)$, and $59.6 \%$ (min $20 \%$ to $\max 90 \%$ ) respectively.

On follow up evaluation and biopsy examination, we found cancer in 8 cases. There were two false positive cases on pap smears, and two were misdiagnosed as radiation atypia. All cancer cases on CCBs and three suspicious of cancer cases were diagnosed as malignant on biopsies. Other cases were followed up for 1 year; however, follow up was available in 14 cases. Out of 14 cases 3 had recurrences, in which one had a vaginal recurrence with liver metastasis and others have lung metastasis and nodal recurrences without local site recurrences. All the cases of post radiation dysplasia on cell blocks did not show any recurrences on one year follow up.

The Kappa agreements for the pap test, CCB test, $\mathrm{CCB}+\mathrm{p} 16 \mathrm{INK} 4 \mathrm{a}$ and $\mathrm{CCB}+\mathrm{Ki} 67 \geq 20 \%$ tests were $0.352,0.490,0.300$, and 1.000 respectively $(p<0.001)$.

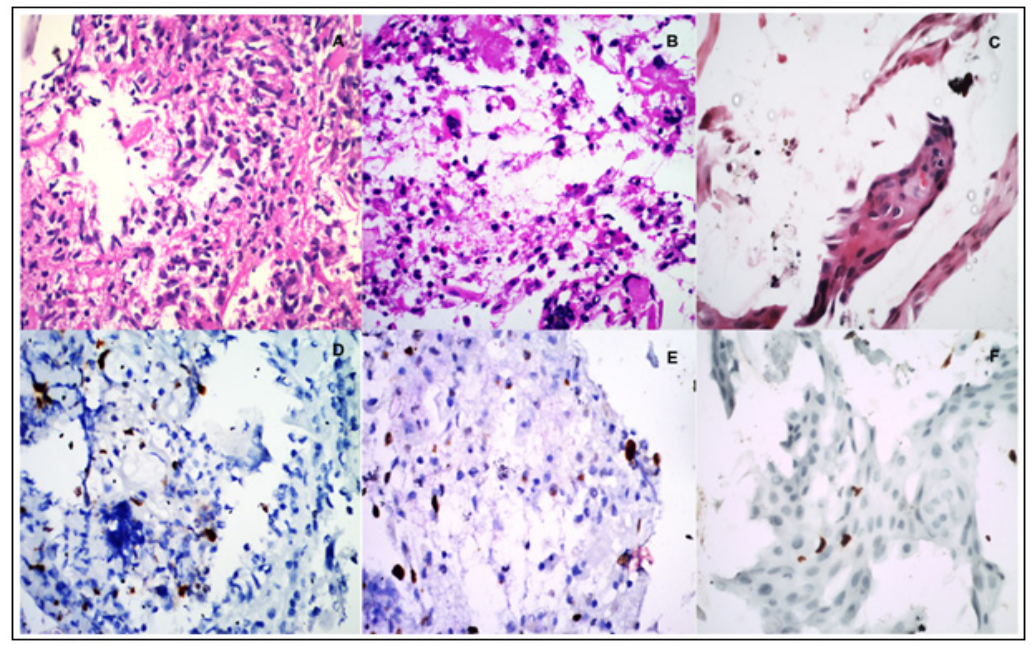

Figure 2. (A) Inflammatory cells H\& E 40 x (B) Post Radiation Dysplasia H\&E 40X (C) Cytological Atypia Suspicious of Malignancy H \& E, 40x (DEF) Ki 67 Expression on (A (B), (C),40x. 
Table 1. Cross-sectional Sensitivity, Specificity, PPV, NPV and Diagnostic Accuracy of Different Tests for Detecting Recurrence or Residual Disease

\begin{tabular}{|c|c|c|c|c|c|}
\hline Diagnostic Test & $\begin{array}{c}\text { Sensitivity } \% \\
(95 \% \mathrm{CI})\end{array}$ & $\begin{array}{l}\text { Specificity } \% \\
(95 \% \text { CI })\end{array}$ & $\begin{array}{c}\text { PPV\% } \\
(95 \% \mathrm{CI})\end{array}$ & $\begin{array}{l}\text { NPV\% } \\
(95 \% \mathrm{CI})\end{array}$ & $\begin{array}{l}\text { Accuracy\% } \\
(95 \% \mathrm{CI})\end{array}$ \\
\hline \multicolumn{6}{|l|}{ Pap test } \\
\hline Suspicious + & $\begin{array}{c}75 \\
(34.9-96.8)\end{array}$ & $\begin{array}{c}74.07 \\
(53.7-88.9)\end{array}$ & $\begin{array}{c}46.15 \\
(28.8-64.5)\end{array}$ & $\begin{array}{c}90.91 \\
(74.7-97.10)\end{array}$ & $\begin{array}{c}74.29 \\
(56.7-87.5)\end{array}$ \\
\hline \multicolumn{6}{|l|}{ CCB test } \\
\hline Suspicious + & $\begin{array}{c}100 \\
(63.1-100.0)\end{array}$ & $\begin{array}{c}88.89 \\
(70.8-97.7)\end{array}$ & $\begin{array}{c}72.73 \\
(47.9-88.6)\end{array}$ & $\begin{array}{c}100 \\
-\end{array}$ & $\begin{array}{c}91.43 \\
(76.9-98.2)\end{array}$ \\
\hline $\mathrm{CB}+\mathrm{P} 16$ cytology & $\begin{array}{c}37.5 \\
(8.5-75.5)\end{array}$ & $\begin{array}{c}96.3 \\
(81.0-99.9)\end{array}$ & $\begin{array}{c}75 \\
(26.5-96.2)\end{array}$ & $\begin{array}{c}83.87 \\
(75.2-89.9)\end{array}$ & $\begin{array}{c}82.86 \\
(66.4-93.4)\end{array}$ \\
\hline \multirow[t]{2}{*}{$\begin{array}{l}\mathrm{CB}+\mathrm{Ki} 67 \text { with cut off } 20 \% \\
\text { (disease present if } \geq 20 \% \text { ) }\end{array}$} & 100 & 100 & 100 & 100 & 100 \\
\hline & $(63.1-100.0)$ & $(87.2-100.0)$ & - & - & $(90.0-100.0)$ \\
\hline
\end{tabular}

The cross-sectional sensitivity, specificity, positive predictive value (PPV), negative predictive value (NPV) and diagnostic accuracy of the abnormalities are presented in Table 1. The STARD flow diagrams for Pap test, CB test, CB with Ki67 index tests are uploaded as supplementary files.

\section{Discussion}

Diagnostic accuracy of post therapy Papanicolaou (pap) tests is low, as it is difficult to differentiate benign from malignant lesions due to post radiation cellular changes. Conventional cell blocks (CCBs) with biomarkers have been found to improve the diagnostic accuracy of cervical cancer detection before therapy [17] however they have not been evaluated in post therapeutic surveillance. In the present study, we evaluated the cross-sectional accuracy of CCB with p16INK4a and Ki67 biomarkers and compared it with conventional pap tests. We found that $\mathrm{CCB}$ has better diagnostic accuracy than conventional pap smear (MacNemar $\mathrm{p}$ value $<0.027$ ) in post therapy cytology.
CCBs samples are like mini-biopsies. After radiation therapy, due to extensive fibrosis and atrophy of the cervical and vaginal epithelium, the epithelium becomes dry and fragile and this makes collection of an adequate population of epithelial cells difficult. On pap smears they appear as fragments and misinterpreted as malignancy [20]. However, we identified these fragments as atrophy or benign glandular lesions on CCBs. We could also identify adenocarcinoma on CCBs which was diagnosed as suspicious of malignancy on pap smear; findings similar to observations made by Desai et al. [17], who reported that CCBs can correctly identify glandular lesions.

We have detected site recurrences and persistent disease in 8 out of $35(22 \%)$ cases with cell blocks and $\mathrm{Ki} 67$ index $\geq 20 \%$. Pap test alone detected site recurrences in $17.1 \%$ ( 6 out of 35 patients). The Cohen's kappa agreement value for Ki67 labeling index with cut off $20 \%$ was 1.00 , which was similar to the reference standard results $(\mathrm{p}<0.001)$. This result suggests that $\mathrm{Ki} 67$ index $\geq 20 \%$ on CCBs can differentiate radiation atypia from cervical cancer. We have observed that increased

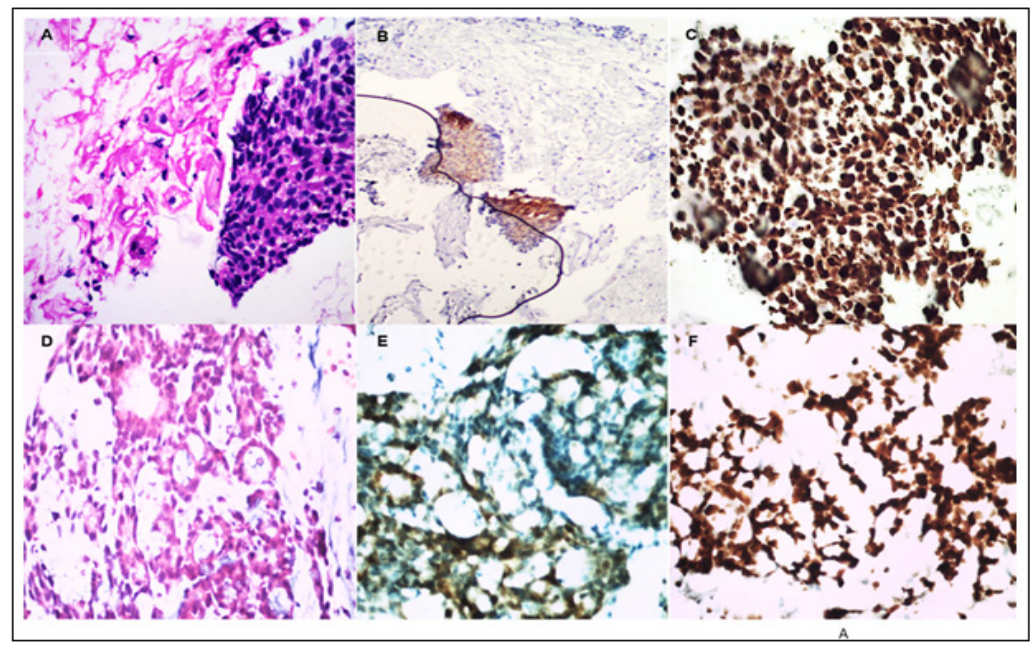

Figure 3. (A) Poorly Differentiated Squamous Cell Carcinoma H\& E, 40x (B) P16 INK4a Weak Expression, on (A) 4x,(C) Ki67 Expression on A,40x (D) Adenocarcinoma. H\&E,40x (E) P16 INK4a Weak Expression on D,40x (F) Ki 67 Expression on D, $40 \mathrm{x}$ 


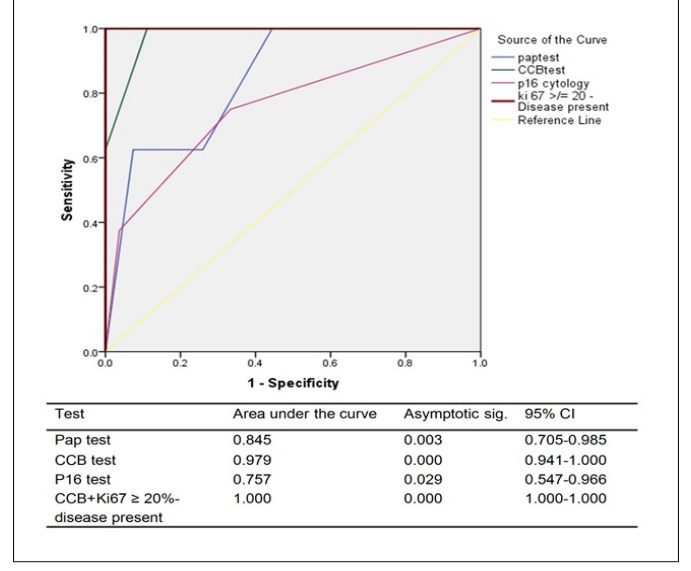

Figure 4. Receiver Operating Characteristic (ROC) Curve for Detecting Residual Disease or Recurrences

inflammatory cells and reactive stromal cells showed increased Ki67 indices, however they showed scattered rather than fragment like pattern (Common in tumors) [17] and their Ki 67 labeling indices were less than 16\%. Radiation can induce cytological changes in benign and malignant epithelia like increased cytoplasm (with preservation of nuclear-cytoplasmic ratio), cytoplasmic vacuoles, eosinophilia, polychromasia, multinucleated giant cells, nuclear membrane blebbing, nuclear karyorrhexis and pyknosis. It also activates repair cells, atypical stromal cells, endothelial cells and macrophages [18]. In this situation, only strong nuclear expression [21] and high hot spot count on morphologically abnormal epithelial cells in tight clusters can avoid pitfalls during interpretation. Malignant cells may be present after completion of the treatment and can be considered as a significant indicator of tumour recurrence or persistence only if they are present in smears 1 month or more after the completion of treatment $[12,18,22]$. The p16INK4a expression in post therapy cancers varied. We found weak p16INK4a expression in both benign atrophic epithelia and post therapy cancers. We did not find any statistical association between 16 expression and post therapy cervical cancer.

One of the limitations of our study is a small sample size. We did not study the patients during ongoing therapy or earlier than one year, neither we could compare the tests with PET/CT findings. We could not follow all the patients. In the present study, inflammatory cells and macrophages were identified based on morphology only as we could not use PanCK and CD 68 markers because of resource limitation. The method described in present study is for cervicovaginal samplings and it could not detect distant metastasis or other than site recurrences.

Thus, our findings suggest that Ki 67 labeling index $\geq$ $20 \%$ on post therapy conventional cell blocks preparations can identify persistent or recurrent cervical cancer. More conventional CCBs have better accuracy than conventional pap tests. We also observed that p16INK4a is not much useful as a biomarker in evaluation recurrence/ residual disease.

\section{References}

1. Arbyn M, Weiderpass E, Bruni L, de Sanjosé S, Saraiya M, Ferlay J, Bray F. Estimates of incidence and mortality of cervical cancer in 2018: a worldwide analysis. The Lancet Global Health. 2020 02;8(2):e191-e203. https://doi. org/10.1016/s2214-109x(19)30482-6

2. Gaffney DK, Erickson-Wittmann BA, Jhingran A, Mayr NA, Puthawala AA, Moore D, Small W, Varia MA, Wolfson AH, Yashar CM, Yuh W, Cardenes HR. ACR Appropriateness Criteria ${ }^{\circledR}$ on Advanced Cervical Cancer Expert Panel on Radiation Oncology - Gynecology. International Journal of Radiation Oncology*Biology*Physics. 2011 Nov;81(3):609614. https://doi.org/10.1016/j.ijrobp.2010.11.005

3. Koh W, Abu-Rustum NR, Bean S, Bradley K, Campos SM, Cho KR, et al. Cervical Cancer, Version 3.2019, NCCN Clinical Practice Guidelines in Oncology. Journal of the National Comprehensive Cancer Network. 2019 01;17(1):64-84. https://doi.org/10.6004/jnccn.2019.0001

4. Salani R, Khanna N, Frimer M, Bristow RE, Chen L. An update on post-treatment surveillance and diagnosis of recurrence in women with gynecologic malignancies: Society of Gynecologic Oncology (SGO) recommendations. Gynecologic Oncology. 2017 07;146(1):3-10. https://doi. org/10.1016/j.ygyno.2017.03.022

5. Zanagnolo V, Minig LA, Gadducci A, Maggino T, Sartori E, Zola P, Landoni F. Surveillance Procedures for Patients for Cervical Carcinoma: A Review of the Literature. International Journal of Gynecologic Cancer. 2009 03;19(3):306-313. https://doi.org/10.1111/igc.0b013e3181a130f3

6. Wright JD, Herzog TJ, Mutch DG, Gibb RK, Rader JS, Davila RM, Cohn DE. Liquid-based cytology for the postirradiation surveillance of women with gynecologic malignancies. Gynecologic Oncology. 2003 Oct;91(1):134-138. https:// doi.org/10.1016/s0090-8258(03)00509-2

7. Chien C, Ting L, Hsieh C, Lai M. Post-radiation Pap smear for Chinese patients with cervical cancer: a ten-year follow-up. European Journal of Gynaecological Oncology. 2005;26(6):619-22.

8. Injumpa N, Suprasert $\mathrm{P}$, Srisomboon J, Nimmanahaeminda $\mathrm{K}$, Phongnarisorn C, Siriaree S, et al. Limited value of vaginal cytology in detecting recurrent disease after radical hysterectomy for early stage cervical carcinoma. Asian Pac J Cancer Prev. 2006;7(4):656-8.

9. Zannoni GF, Vellone VG. Accuracy of Papanicolaou Smears in Cervical Cancer Patients Treated With Radiochemotherapy Followed by Radical Surgery. American Journal of Clinical Pathology. 2008 Nov;130(5):787-794. https://doi. org/10.1309/ajcpp1zwk8emhbcz

10. Lucena FA, Costa RFA, Stein MD, Andrade CEMC, Cintra GF, Vieira MA, Dufloth RM, Fregnani JHTG, dos Reis R. Pelvic radiotherapy for cervical cancer affects importantly the reproducibility of cytological alterations evaluation. BMC Clinical Pathology. 2018 Oct $05 ; 18(1)$. https://doi. org/10.1186/s12907-018-0078-z

11. Aksu G, Fayda M, Saynak M, Tore G, Alatli C. Is early postradiation dysplasia almost associated with poor prognosis? A case report and review of the literature. International Journal of Gynecological Cancer. 2006 03;16(2):934-936. https://doi.org/10.1111/j.15251438.2006.00216.x

12. Shield Pw, Daunter B, Wright Rg. Post-irradiation cytology of cervical cancer patients. Cytopathology. 1992 06;3(3):167182. https://doi.org/10.1111/j.1365-2303.1992.tb00043.x

13. Salcedo MP, Milbourne AM, Jhingran A, Eifel PJ, Ramirez PT, Schmeler KM. High-Grade Cervical Dysplasia following 
Radiation Therapy for Invasive Cervical Cancer: A Report of Four Cases. Case Reports in Oncology. 201505 06;8(2):217221. https://doi.org/10.1159/000382117

14. Ryu S, Kim M, Choi S, Choi C, Lee K. Detection of early recurrence with $18 \mathrm{~F}-\mathrm{FDG}$ PET in patients with cervical cancer. J Nucl Med. 2003;44(3):347-52.

15. Viswanathan C, Faria S, Devine C, Patnana M, Sagebiel T, Iyer RB, Bhosale PR. [18F]-2-Fluoro-2-Deoxy-Dglucose-PET Assessment of Cervical Cancer. PET Clinics. 2018 04;13(2):165-177. https://doi.org/10.1016/j. cpet.2017.11.004

16. Ulaner GA, Lyall A. Identifying and Distinguishing Treatment Effects and Complications from Malignancy at FDG PET/CT. RadioGraphics. 2013 Oct;33(6):1817-1834. https://doi.org/10.1148/rg.336125105

17. Desai F, Singh LS, Majachunglu G, Kamei H. Diagnostic Accuracy of Conventional Cell Blocks Along with p16INK4 and Ki67 Biomarkers as Triage Tests in Resource-poor Organized Cervical Cancer Screening Programs. Asian Pacific Journal of Cancer Prevention. 201903 01;20(3):917923. https://doi.org/10.31557/apjcp.2019.20.3.917

18. Nayar R, Wilbur D. The Bethesda System for Reporting Cervical Cytology: Definitions, Criteria, and Explanatory Notes, edition 3. . New York: Springer;2015.

19. Amin M, Edge S, Greene F. AJCC Cancer Staging Manual (8th edition). New York: Springer International Publishing: American Joint Commission on Cancer. 2017;:649-50.

20. Dorr W, Engenhart-Cabillic R, Zimmermann J. Normal Tissue Reactions in Radiotherapy and Oncology. Banglore: Karger, Panther Publishers Private Limited. 2002;:113-8.

21. Nakano T, Oka K. Transition of Ki-67 index of uterine cervical tumors during radiation therapy. Immunohistochemical study. Cancer. 1991;68(3):517-23.

22. Padilha CML, Araújo Junior MLC, Souza SALD. Cytopathologic evaluation of patients submitted to radiotherapy for uterine cervix cancer. Revista da Associação Médica Brasileira. 2017 04;63(4):379-385. https://doi. org/10.1590/1806-9282.63.04.379

\section{(c) (i) (8)}

This work is licensed under a Creative Commons AttributionNon Commercial 4.0 International License. 